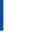

\title{
Government green-lights HPV virus for boys
}

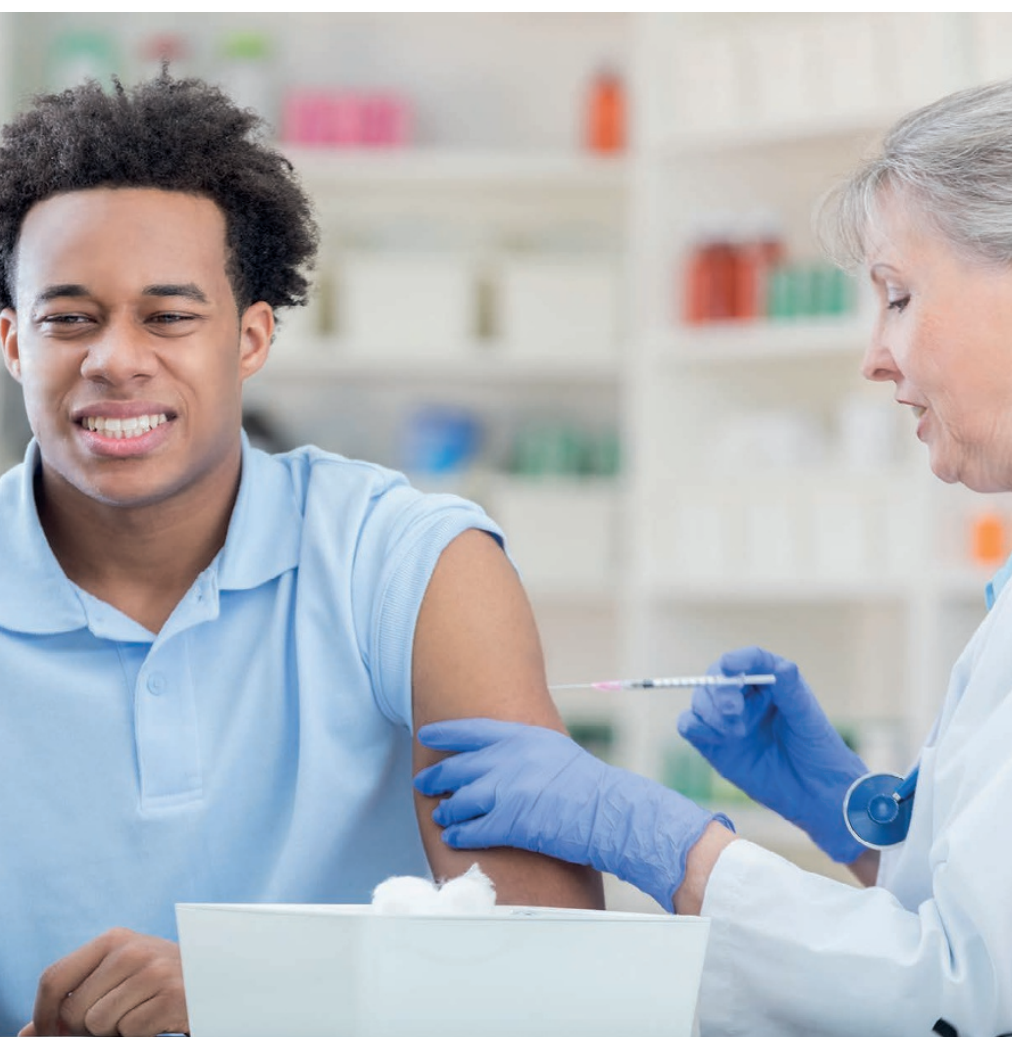

$\mathrm{T}$ he government has confirmed that adolescent boys will be offered the human papilloma virus (HPV) vaccine to protect them from cancer.

The announcement made on 24 July 2018 followed a recommendation a few days earlier from influential government advisers who said yes to extending the HPV vaccination to boys as well as girls after much campaigning by various health professions (including dentists) and experts.

The government's scientific advisory body the Joint Committee on Vaccination and Immunisation (JCVI) announced in a statement issued on 18 July 2018 that it was recommending extending immunisation to adolescent boys at the same age as adolescent girls (12-13 years) because it had concluded that a combined vaccination programme was 'highly likely to be cost-effective.'

It is estimated that around 400,000 boys will benefit from the decision, subject to ministers negotiating an effective rate on bulk purchasing of the vaccine.

HPV affects $80 \%$ of men at some point in their lives, causes $5 \%$ of all cancers and is the leading cause of oropharyngeal cancers.

Subsequently, the Department of Health and Social Care said it was accepting the JCVI recommendation and Public Health Minister Steve Brine said: 'The HPV vaccine for girls is already expected to save hundreds of lives every year and I am delighted that we will now be protecting even more people from this devastating disease by extending the vaccines to boys.
'We are committed to leading a world-class vaccination programme and achieving some of the best cancer outcomes in the world - I am confident these measures today will bring us one step further to achieving this goal.'

Dr Mary Ramsay, Head of Immunisations at Public Health England, said: 'Almost all women under 25 have had the HPV vaccine and we're confident that we will see a similarly high uptake in boys.

'This extended programme offers us the opportunity to make HPVrelated diseases a thing of the past and build on the success of the girls' programme, which has already reduced the prevalence of HPV 16 and 18 , the main cancer-causing types, by over $80 \%$.

Peter Baker, Campaign Director for campaigning group HPV Action, welcomed the announcement, saying: 'We have waited five years for this because the JCVI began assessing whether boys should be vaccinated back in 2013 .

'This is really welcome and the final piece in the jigsaw is getting the Department of Health and Social Care and governments in the other devolved administrations to announce that they will implement the JCVI recommendation.'

Scotland and Wales' administrations have also said that they will fund the JCVI's recommendations but confirmation for Northern Ireland was still to be made as this issue of the $B D J$ went to press.

Roz McMullan, Chair of the BDA Northern Ireland Council said: 'We're pleased to hear the news that the HPV vaccine has been recommended to be extended to boys in England, and Scottish and Welsh Governments have confirmed they will provide the funding, but we will now work to insist that Northern Ireland follows suit.

'Working with Cancer Focus Northern Ireland, we are asking the Department of Health in Stormont to provide urgent clarity on whether the funding will be made available to ensure boys in

\section{'We have waited five years for this because the JCVI began assessing whether boys should be vaccinated back in 2013' - Peter Baker}

Northern Ireland will also benefit from receiving the HPV vaccine.'

HPV Action's Peter Baker added: 'This has dragged on for long enough and we need them to say that they will go ahead with this and to start planning implementation.'

Realistically, it was likely, he said, that boys could start being vaccinated at the start of the 2019 school year, meaning around September of next year at an estimated cost of $£ 22$ million extra per year, although the government could negotiate a cheaper price with manufacturers.

'It should be straight forward to extend this programme for the boys. They will have to prepare information materials for boys 
4 and parents, train school nurses in the rationale for the decision, and the vaccine manufacturers will have to gear up their production, but this is all very do-able.

'The important thing is now to move ahead as quickly as possible.'

The BDA has called for a gender-neutral approach to the vaccinations for some time stressing the fact that HPV has become the leading cause of throat cancers, especially among young people, and rates are rising overall.

More than 30 people in Britain are diagnosed with oral (including mouth and throat) cancers every day and during the last decade, oral cancer incidence rates have increased by almost a quarter (23\%) in the UK.

Fifteen countries are already vaccinating boys or plan to do so, including Australia, Austria, Barbados, Bermuda, Brazil, Canada, Croatia, Czech Republic, Italy, Liechtenstein, New Zealand, Norway, Serbia, Switzerland and the United States of America.

BDA Chair Mick Armstrong said: 'This decision will save lives. When our NHS faces such sustained pressure from so many preventable conditions, from cancers, to tooth decay and obesity, this sort of cost-effective intervention must not be a one off.

'Health professionals need this breakthrough on HPV to mark the beginning, and not the end, of this government's willingness to invest in prevention.'

The Faculty of General Dental Practice (FGDP [UK]) also welcomed the news and its Dean Ian Mills said: 'Oral cancer is a serious and potentially devastating condition, and the more we can do to prevent it, the better.
'The whole dental team plays an important role in delivering advice on the prevention of oral cancer and diagnosing potentially malignant lesions early'

The British Association of Oral and Maxillofacial Surgeons (BAOMS) said the decision would help to save lives and money.

BAOMS Chair Patrick Magennis said: 'The actual cost of annual vaccination is estimated to be a quarter of the cost of treatment of just HPV-driven oropharyngeal cancers (cancers of the tonsil, base of

\section{'This decision will save lives. Health professionals need this breakthrough on HPV' - Mick Armstrong}

tongue and side of the throat), let alone the cost to individuals who have suffered an HPV-related cancer. The arguments to introduce the vaccination programme are clear.

'Current evidence suggests that vaccination of boys in their teenage years will prevent them from developing HPV-related cancers in middle age. The introduction of male vaccination is both timely and a welcome first step.

1. Joint Committee on Vaccination and Immunisation. Statement on HPV vaccination (July 2018). https://assets. publishing.service.gov.uk/government/uploads/system/uploads/ attachment_data/file/726319/JCVI_Statement_on_HPV_vaccination_2018.pdf (accessed on 18 July 2018). 